\title{
Comércio exterior inter e intra-industrial: Brasil 2003-2005 ${ }^{1}$
}

\author{
Carolina Troncoso Baltar ${ }^{2}$
}

\begin{abstract}
Resumo
O período 2003-2005 foi marcado pelo intenso crescimento do comércio mundial. Neste contexto, o Brasil foi capaz de reverter seu déficit de comércio, usufruindo de expressivo superávit. Porém, este dinamismo comercial não foi acompanhado de crescimento da economia nacional. Este trabalho faz uma análise empírica do comércio brasileiro neste período recente de expansão do comércio mundial, com o objetivo de relacionar o tipo de comércio brasileiro com as características da estrutura industrial que existe no país. A metodologia adotada traz como novidade a possibilidade de se avaliar o comércio de uma perspectiva mais qualitativa, a partir do exame do tipo de produto e região de origem e destino dos fluxos.
\end{abstract}

Palavras-chave: Brasil - Comércio Exterior; Desenvolvimento econômico; Organização industrial.

\begin{abstract}
Inter and intra industrial external trade: Brazil 2003-2005

The period between 2003-2005 illustrated a high growth in world trade. In this context, Brazil was able to revert its trade deficit, taking advantage of a considerable surplus. Nevertheless, this trade dynamism did not go hand in hand with national economic growth. This article makes an empirical analysis of Brazilian trade in this recent period of world trade expansion, with a view to comparing the kinds of Brazilian trade with the industrial structure that exists in this country. The methodology adopted is innovative in that it allows the evaluation of trade from a qualitative perspective, by examining the kind of product and region of origin and destination of the flows.
\end{abstract}

Key words: International trade; Economic development; Industrial organization. JEL F000, F100, F120.

\section{Introdução}

O período 2003-2005 foi marcado pelo intenso crescimento do comércio mundial. Neste contexto, o Brasil foi capaz de reverter seu déficit de comércio, passando a usufruir de expressivo superávit. Porém, este dinamismo comercial não foi acompanhado de um crescimento mais intenso da economia nacional.

A semi-estagnação coloca em discussão o que deve ser implementado para se obter uma retomada mais firme da atividade econômica, aumentando a taxa de investimento e o ritmo de crescimento do produto. Uma questão central na

(1) Trabalho recebido em março de 2007 e aprovado em setembro de 2007.

(2) Doutoranda no Departamento Land Economy na Universidade de Cambridge, Inglaterra. E-mail: $<$ cbaltar@gmail.com>. 
discussão deste assunto é o papel das exportações para esta retomada da atividade econômica. O desempenho das exportações brasileiras ao longo dos anos 1990 ficou aquém do ritmo de crescimento do comércio mundial das exportações. Este modesto crescimento está relacionado com a composição da pauta exportadora brasileira, por tipo de produto e país de destino, porém esta relação é complexa. De fato, salvo as exportações para os Estados Unidos que têm um conteúdo tecnológico relativamente mais avançado, os produtos manufaturados de maior elaboração são exportados principalmente para países em desenvolvimento, em particular a América Latina, enquanto os produtos exportados para a União Européia e Ásia são principalmente produtos primários ou semi-elaborados (Prates, 2006).

Com esta pauta, o dinamismo das exportações depende de um nível sustentado da atividade econômica nos países em desenvolvimento, que importam produtos manufaturados brasileiros, além de crescimento da demanda mundial por produtos primários e semi-elaborados. Este crescimento da demanda mundial por produtos primários e semi-elaborados tem dois efeitos sobre as exportações brasileiras: afeta diretamente as exportações brasileiras de produtos primários e semi-elaborados, e beneficia indiretamente as exportações de manufaturados, ao permitir aumentar a atividade econômica nos países em desenvolvimento, importadores desses produtos brasileiros, que são também exportadores de produtos primários e semi-elaborados.

Durante a década de 1990, a demanda mundial por produtos primários manteve-se contida, prejudicando, direta e indiretamente, as exportações brasileiras. A manutenção de um câmbio valorizado não fez mais do que agravar as dificuldades brasileiras para aumentar as suas exportações, de modo a conter o crescente déficit de conta corrente do balanço de pagamentos que aconteceu no Brasil na década de 1990. O câmbio valorizado colocou problemas adicionais para a realização dos investimentos necessários para consolidar as exportações, e eventualmente modificar a pauta, introduzindo novos produtos e diversificando os países de destino, passando a exportar manufaturados mais sofisticados para paises desenvolvidos.

A relação entre comércio exterior e crescimento depende muito do conteúdo de elaboração dos produtos e da agregação de valor que existe na produção destes bens. Essa consideração é importante para o crescimento, especialmente tratando-se de um país em desenvolvimento, que está montando sua estrutura de produção. Porém, na discussão do desenvolvimento e, portanto, da mudança estrutural de uma economia, o exame dos fluxos de comércio por tipo de produto e país de origem e destino das importações e exportações, deve ressaltar a questão da transformação industrial e do valor agregado, que incide na intensidade 
do aumento do produto industrial e em suas repercussões no crescimento do conjunto da economia.

A idéia é de que os setores de atividade têm impactos diferentes no crescimento de uma economia. Kaldor formulou algumas proposições sobre a dinâmica intersetorial do processo de crescimento (Thirlwall, 2000). A primeira delas diz que o potencial de crescimento do conjunto de uma economia depende do ritmo de crescimento de setor manufatureiro, que é o setor portador de inovação. A segunda diz que existe uma forte relação causal positiva entre crescimento do produto manufatureiro e crescimento da produtividade manufatureira, como resultado dos retornos de escala estáticos e dinâmicos. Esta proposição também ficou conhecida na literatura como lei de Verdoorn. Por fim, uma última proposição diz que existe uma forte relação causal positiva entre a taxa de crescimento do setor manufatureiro e o crescimento da produtividade fora do setor manufatureiro.

Ainda seguindo o raciocínio de Kaldor, a grande questão seria o que determina o crescimento do setor manufatureiro, já que este é tido como o dinamizador do crescimento da economia como um todo. Por definição, a manufatura é o setor de atividade que tem retornos crescentes, estáticos e dinâmicos. O aproveitamento dessas possibilidades de ampliar a produção, reduzindo o custo, exige o crescimento da venda dos produtos. Esta ampliação das vendas está associada às mudanças de produtos e redução de custo provocada pela inovação (segunda proposição de Kaldor). Isto ocorre não somente na manufatura, mas também nos setores que utilizam os produtos aperfeiçoados pela manufatura (terceira proposição de Kaldor). Portanto, o que determina o crescimento do setor manufatureiro é fundamentalmente o seu potencial de criar novos produtos e reduzir os custos dos produtos existentes. A possibilidade de obtenção de lucros maiores com esses novos produtos e processos provocam investimentos, que vão além dos induzidos pela simples ampliação das vendas dos produtos existentes. Estes investimentos autônomos que ocorrem na manufatura e nos outros setores que utilizam os produtos aperfeiçoados pela manufatura, e seus efeitos indiretos sobre o consumo, geram a demanda pelos produtos que permite efetivar as possibilidades de retornos crescentes, estáticos e dinâmicos, que caracterizam o setor manufatureiro.

Numa economia aberta, os outros países são potenciais compradores de produtos elaborados pela manufatura, e o país pode importar produtos manufaturados de outros países. Através do comércio, as economias repartem entre si os efeitos dinâmicos, diretos e indiretos, associados à existência de retornos crescentes, estáticos e dinâmicos, próprios da manufatura. No caso de uma repartição equilibrada desses efeitos dinâmicos, as exportações também poderão ter um papel fundamental na dinâmica do crescimento da economia, 
atuando como um componente autônomo, ao lado do investimento portador de inovações, promovendo o crescimento da renda nacional muito mais do que sendo induzido por este crescimento. Além disso, as exportações permitem pagar as importações, que se tornam necessárias ao desenvolvimento de um país. Neste caso, elas não têm apenas o efeito direto de promover o crescimento, mas também os efeitos indiretos, por permitirem que os outros componentes da demanda, inclusive o investimento, aumentem mais rápido do que fariam sem as importações. Ou seja, o intercâmbio com outros países, na medida em que é capaz de proporcionar produtos mais abundantes e baratos, contribui para que ocorram maiores investimento, consumo e mesmo exportações. No caso de uma repartição desequilibrada dos efeitos dinâmicos entre os países, o comércio torna-se uma restrição ao crescimento do país que não conseguir desenvolver as atividades com retornos crescentes, estáticos e dinâmicos. Um crescimento mais intenso dessas economias tenderia a provocar uma expansão das importações em ritmo mais elevado do que o das exportações.

A relação entre crescimento e estrutura de comércio é, então, de grande importância. Este trabalho faz uma análise empírica do comércio brasileiro no período recente de expansão do comércio mundial, com o objetivo de relacionar o tipo de comércio brasileiro com as características da estrutura industrial que existe no país. A metodologia adotada traz como novidade a possibilidade de se avaliar o comércio de uma perspectiva mais qualitativa, a partir do exame do tipo de produto e região de origem e destino dos fluxos.

\section{Metodologia}

\subsection{Indicadores tradicionais de comércio}

Num panorama geral da evolução do comércio entre os países, desde o século XX, constatou-se, de um lado, a crescente importância dos produtos manufaturados em detrimento dos produtos primários e, de outro, a crescente participação no comércio mundial dos países mais industrializados. Esse resultado, em grande medida, reflete o fato de que o desenvolvimento da produção de bens envolveu uma enorme diversificação dos produtos manufaturados que, inclusive, substituíram uma série de produtos primários. O comércio de produtos manufaturados entre países mais desenvolvidos facilitou a ampliação da variedade dos produtos e o aproveitamento das economias da produção em grande escala. É possível distinguir o tipo de comércio em função do grau de desenvolvimento dos países envolvidos. No caso do comércio entre países com graus de desenvolvimento muito diferentes, o intercâmbio tende a ser de produtos de setores diferentes (intersetorial). Já no caso do comércio entre países com graus semelhantes de desenvolvimento, tende a ser maior o peso do intercâmbio de produtos dos mesmos setores (intra-industrial). Os indicadores de comércio 
procuram exprimir essas diferenças de tipos de comércio (Fontagné; Freudenberg, 1997).

Os indicadores sobre comércio internacional foram inspirados pela decomposição do comércio total em uma parcela de comércio equilibrado (sobreposição entre exportações e importações) e uma parcela de comércio desequilibrado (superávit ou déficit). Considerando uma economia de dois setores, com comércio global equilibrado, o grau intra-setorial do comércio pode ser medido a partir do peso dos saldos no comércio de cada um dos setores. Os dois casos extremos são: primeiro, os dois setores têm comércio equilibrado, o que permite dizer que o comércio da economia é intra-setorial; e, segundo, um setor só tem exportação e o outro, apenas importação, sendo o comércio da economia interindustrial. Os casos intermediários dependem do montante do desequilíbrio do comércio de cada setor em relação ao total deste comércio.

Um dos primeiros indicadores para medir a composição inter e intraindustrial do comércio entre os países foi o de Balassa ${ }^{3}$ :

$$
\mathrm{Bj}=\frac{X_{j}-M_{j}}{X_{j}+M_{j}}=\frac{\frac{X_{j}}{M_{j}}-1}{\frac{X_{j}}{M_{j}}+1}, \text { em que }
$$

$\mathrm{X}$ representa a exportação da indústria j, e

M representa a importação da indústria j.

De acordo com este indicador, o comércio do setor é interindustrial quando o saldo é muito grande, e é intra-industrial quando há um equilíbrio entre exportação e importação do setor. Se $\mathrm{Bj}$ for igual a -1 , o comércio é interindustrial com desvantagens comparativas para o setor. Se for igual a zero é intra-industrial. E se for igual a 1, o comércio é interindustrial com vantagens comparativas para o setor.

Outro indicador, derivado do de Balassa, e um dos mais usados para medir a extensão do comércio intra-industrial, foi elaborado por Grubel e Lloyde (GL), que procura medir o valor da sobreposição entre exportações e importações no comércio total de uma indústria j dada:

$$
\mathrm{GLj}=\frac{X_{j}+M_{j}-\left|X_{j}-M_{j}\right|}{X_{j}+M_{j}}=1-\frac{\left|X_{j}-M_{j}\right|}{X_{j}+M_{j}} .
$$

(3) Uma discussão mais detalhada deste e de outros indicadores de comércio entre países pode ser encontrada em Fontagné e Freudenberg (1997). 
Este indicador varia entre 0 e 1 . Quando o valor das exportações for semelhante ao valor das importações, isto é GL próximo de 1, o comércio é classificado como intra-industrial, e caso contrário, interindustrial.

Fontagné e Freudenberg (1997) apontam algumas imperfeições deste indicador. Uma delas é que parte importante do comércio intra-industrial pode ser apenas aparente em consequiência de uma desagregação geográfica ou setorial insuficiente. Cada um dos setores elabora diversos produtos, e é possível que o setor exporte alguns produtos e importe outros. No conjunto do setor, o comércio é equilibrado, mas para cada produto o desequilíbrio pode ser grande. Além disso, o setor pode exportar para um país e importar de outro. Neste caso, o comércio global do setor pode estar equilibrado, mas o desequilíbrio pode ser grande no comércio com cada país.

\subsection{Indicadores alternativos de comércio}

Fontagné e Freudenberg (1997) apontam para a necessidade de um método que: minimize os problemas de agregação setorial e geográfica, utilizando uma classificação mais desagregada por produto e países de origem das importações e destino das exportações. Para cada produto e país, o comércio é unilateral quando o saldo é grande em relação ao total do comércio. Neste caso, trata-se de um comércio fundamentalmente de uma só via. O comércio será bilateral se o saldo para determinado produto e país for pequeno relativamente ao total do comércio. Neste caso, o comércio com este produto e país é fundamentalmente de duas vias. No caso do comércio de duas vias, distingue-se ainda simples diferenças horizontais de diferenças verticais, em função da diferença de qualidade do produto, expressada pelos preços. Uma metodologia que incorpora essas considerações será utilizada neste trabalho, partindo dos indicadores de Abd-El-Rahman e Fontagné e Freudenberg (Fontagné; Freudenberg, 1997). Assim distinguiram-se três tipos de comércio. Em primeiro lugar, o comércio unilateral de produtos que são exportados ou importados de um determinado país. Em segundo lugar, o comércio bilateral, em que se exporta e importa de determinado país produtos horizontalmente diferenciados, em que as variedades exportadas e importadas situam-se num mesmo grau de qualidade. E, em terceiro lugar, o comércio bilateral de produtos verticalmente diferenciados, em que há diferenças de qualidade entre os produtos exportados e importados. Assume-se que diferenças em preços (valores unitários) refletem diferenças em qualidade.

Para fazer a distinção entre o comércio unilateral e o bilateral, foi utilizado o Índice de Sobreposição do Comércio:

$$
\text { ISC }=\frac{\operatorname{Min}\left(X_{r, p, t} ; M_{r, p, t}\right)}{\operatorname{Max}\left(X_{r, p, t} ; M_{r, p, t}\right)}, \text { em que }
$$


$\mathrm{X}$ representa a exportação para a região $\mathrm{r}$, do produto $\mathrm{p}$, no tempo $\mathrm{t}$, $\mathrm{e}$

$\mathrm{M}$ a importação da região $\mathrm{r}$, do produto $\mathrm{p}$, no tempo $\mathrm{t}$.

Se ISC for maior do que $10 \%$, o comércio do produto é considerado bilateral, caso contrário, seria unilateral.

Outro índice utilizado é o Índice de Qualidade:

$$
\mathrm{IQ}=\frac{\text { ValorUnitáriodaExportação }_{r, p, t}}{\text { ValorUnitárioda } \operatorname{Im} \text { portação }_{r, p, t}}
$$

Este índice distingue se a diferenciação é horizontal ou vertical. Se IQ estiver entre 0,85 e 1,15 , o produto é diferenciado horizontalmente, caso contrário, a diversificação seria vertical. A diferença de qualidade é captada pela diferença de preços.

Quando o comércio for bilateral vertical, distingue-se a qualidade do fluxo de comércio pelo valor do Índice de Qualidade. Quando IQ for maior do que 1,15, assume-se que o fluxo comercial é de alta qualidade, no sentido de que as exportações têm valor unitário maior do que as importações, e quando for menor do que 0,85 , seria de baixa qualidade.

Espera-se que o comércio bilateral horizontal ocorra entre indústrias de países mais parecidos, já que a qualidade dos produtos é semelhante. No caso do comércio bilateral vertical, a existência de produtos com qualidades distintas reflete a diferença de desenvolvimento industrial. Finalmente, o comércio unilateral prevalecerá entre países que têm dotações de recursos muito diferentes. Em tese, no caso do comércio bilateral vertical superior, em que a qualidade do produto exportado é superior a do produto importado, espera-se que a produção deste produto agregue mais valor, gerando um maior potencial de crescimento para o país. É claro que existe exceções, como a Maquila, que exporta produtos do final da cadeia produtiva, sem necessariamente gerar muito valor agregado. $\mathrm{O}$ segundo caso, o do comércio bilateral vertical inferior, pode ocorrer quando o país está especializado na faixa mais baixa da cadeia de valor, exportando insumos baratos. Isto significa que a agregação de valor na economia também é mais baixa.

\subsection{Classificação dos produtos}

Uma classificação de setores de atividade, agregando os produtos em função do conteúdo tecnológico, e a consideração do grau de desenvolvimento dos países de origem das importações e dos países de destino das exportações, contribuirão para uma melhor especificação do padrão de comércio internacional e sua relação com o desenvolvimento do país. Uma classificação setorial bastante utilizada baseia-se numa tipologia elaborada por Pavitt (Holland; Xavier, 2005). 
Os setores produtores de bens seriam Produtos Primários (Agrícolas, Minerais e Energéticos), Manufaturados Intensivos em Recursos Naturais (Agroindústria, Processamento de Recursos Minerais e Energéticos), Manufaturados Intensivos em Trabalho (Têxtil, Confecções, Calçado, Cerâmica, Editorial e Gráfica, Produtos de Metal), Manufaturados Intensivos em Escala (Automotriz, Siderurgia, Bens Eletrônicos de Consumo), Manufaturados com Fornecedores Especializados (Bens de Capital sob Encomenda, Equipamentos de Engenharia) e Manufaturados Intensivos em P\&D (Química Fina, Componentes Eletrônicos, Telecomunicação, Aviões).

Esta taxonomia associa cada categoria na "tipologia ao fator preponderante que molda o posicionamento competitivo das empresas e setores no curto e no longo prazos. Nas indústrias com tecnologias intensivas em recursos naturais, o principal fator competitivo é o acesso a recursos naturais abundantes existentes no país; nas intensivas em trabalho, o mais relevante é a disponibilidade de mão-de-obra de baixa e média qualificação com custos relativos reduzidos em relação a outros países; nos setores intensivos em escala, as plantas produtivas são caracterizadas por indivisibilidades tecnológicas e, por isso mesmo, o principal fator de competitividade é a possibilidade de explorar ganhos por produzir em grande escala; nos setores com tecnologia diferenciada, os bens são fabricados para atender a diferentes padrões de demanda; e nas indústrias science-based, o principal fator competitivo é a rápida aplicação da pesquisa científica às tecnologias industriais" (Lall, citado por Nassif, 2006, p. 22).

A metodologia desenvolvida por Fontagné e Freudenberg (1997) será utilizada para estudar o comércio do Brasil com todos os blocos econômicos (Mercosul, Nafta, União Européia, Ásia, Aladi e o resíduo, Resto do Mundo). ${ }^{4}$ Os dados são fornecidos pela Secex (Secretaria de Comércio Exterior) e serão analisados a uma desagregação de seis dígitos. Os períodos estudados são 19961998 e 2003-2005, com a intenção de se identificar um determinado padrão de comércio no primeiro período e verificar se este se mantém com as alterações ocorridas após 1999 no mundo e na economia brasileira. Os anos entre 1999 e 2002 não serão utilizados na análise para evitar um viés no resultado, pois houve a crise do Brasil em 1999 e a crise mundial em 2002. Procura-se avaliar, por produto, o tipo de comércio com cada região, esperando que proporcionem elementos que contribuam para o estudo do padrão de comércio do país e sua relação com o potencial de crescimento da economia brasileira. Nesse sentido, é importante levar em conta a estrutura produtiva do país e sua relação com o comércio exterior.

(4) Os países que fazem parte de cada bloco econômico estão no Anexo. 
A análise será separada para os distintos tipos de produtos, de acordo com a classificação de Pavitt. Como será visto posteriormente, espera-se que o comércio bilateral seja maior nos casos dos manufaturados intensivos em escala, produzidos por fornecedores especializados e intensivos em P\&D, entre outras razões porque esses grupos de produtos estão inseridos no comércio que se realiza dentro das grandes corporações. Nos outros casos, dos produtos primários, dos intensivos em recursos naturais e mesmo os manufaturados intensivos em trabalho, pelas próprias características dos produtos, espera-se um maior comércio unilateral.

\section{Resultados}

\subsection{Panorama geral}

A corrente de comércio (soma das exportações e importações) no período de 2003 a 2005 foi, em média, de 157,5 bilhões de dólares FOB por ano, correspondendo $61 \%$ às exportações. $\mathrm{O}$ resultado foi um superávit comercial médio de 34,4 bilhões de dólares (Tabela 1). Comparando com o período 19961998, saímos de um déficit comercial médio de 6,3 bilhões de dólares para um expressivo superávit. Houve crescimento tanto das exportações quanto das importações, porém o crescimento das primeiras foi muito mais intenso.

Tabela 1

Comércio Brasileiro

(valor em US\$ milhões de FOB, média do período, taxa em \%)

\begin{tabular}{l|c|c}
\hline & $1996-1998$ & $2003-2005$ \\
\hline Exportações & $50.610,9$ & $95.949,0$ \\
\hline Importações & $56.879,6$ & $61.525,9$ \\
\hline Saldo Comercial & $(6.268,7)$ & $34.423,0$ \\
\hline Comércio & $107.490,5$ & $157.474,9$ \\
\hline Particip. das Exportações & 47,1 & 60,9 \\
\hline
\end{tabular}

Fonte: Elaboração própria a partir dos dados da Secex.

A mudança cambial em janeiro de 1999 deu início a uma nova fase do comércio exterior do país, mais favorável às exportações. Inicialmente, entretanto, a situação desfavorável do comércio mundial contribuiu para retardar a resposta das exportações à desvalorização do Real. Assim,

o desempenho das exportações em termos de intensidade e destinação foi bastante diferenciado por setor de atividade e, na média, ficou aquém do aumento esperado e desejado. A reversão do saldo comercial - de fortemente deficitário para modestamente superavitário em 2000-2001 - foi decorrência da queda mais que proporcional das importações do que do aumento das exportações, em um quadro 
de relativa instabilidade da demanda doméstica: retração em 1999, recuperação em 2000 e nova desaceleração em 2001. E, mais importante (...): o quadro de produtos com maior intensidade tecnológica permaneceu fortemente deficitário mesmo após a desvalorização cambial, com as importações de produtos de média e alta intensidade tecnológica mantendo-se praticamente inalteradas (Sarti; Sabbatini, 2003, p. 387).

A grande elevação das exportações ocorreu depois de 2002, com o aumento do produto e do comércio mundiais. De acordo com Laplane e Sarti (2006), com uma política macroeconômica freando recorrentemente o crescimento da demanda doméstica, o principal estímulo para a expansão da produção industrial somente poderia vir do exterior. O grande aumento das exportações brasileiras, inclusive de manufaturados, foi resultado de um câmbio favorável e da reativação da economia mundial a partir do estreito relacionamento dos Estados Unidos com a Ásia, que resultou em crescente demanda por insumos das economias asiáticas, especialmente da China, que ajudou a elevar a atividade econômica de países que são habituais compradores de produtos manufaturados brasileiros (Prates, 2006).

Assim, o aumento da demanda por produtos primários das economias asiáticas, que provocou a elevação do preço desses produtos, foi acentuado pela situação de alta liquidez no mercado financeiro internacional, o que provocou efeitos diretos e indiretos sobre as exportações brasileiras. Além dos efeitos imediatos do aumento das exportações de produtos primários para a Ásia e do aumento do valor dessas exportações para a Europa, devido aos aumentos de preços, ocorreram efeitos indiretos a partir do aumento da renda dos outros países em desenvolvimento, que são exportadores de produtos primários e importadores de produtos manufaturados brasileiros. Naturalmente, uma reversão na demanda internacional e nos preços dos produtos primários teria o efeito inverso de provocar uma intensa redução nas exportações brasileiras de produtos primários e manufaturados, traduzindo a vulnerabilidade do país à situação do comércio mundial, associada às peculiaridades da pauta de comércio exterior do Brasil.

Avaliando a composição do comércio por tipo de produto, notamos que o superávit comercial de 34,4 bilhões de dólares, correspondendo a 21,9\% do comércio brasileiro no período de 2003-2005, foi causado tanto pelo aumento do superávit com os produtos primários e com os manufaturados intensivos em recursos naturais, escala e trabalho, quanto pela redução nos déficits com os manufaturados intensivos em $\mathrm{P} \& \mathrm{D}$ e produzidos por fornecedores especializados (Tabela 2). 
Tabela 2

Comércio brasileiro por tipo de produto

(valor em US\$ milhões de FOB, média do período, taxa em \%)

\begin{tabular}{l|c|c|c|c|c|c|c|c|c|c}
\hline & \multicolumn{2}{|c|}{ Exportações } & \multicolumn{2}{|c|}{ Importações } & \multicolumn{2}{c|}{ Comércio } & \multicolumn{2}{c|}{ Saldo } & \multicolumn{2}{c}{$\begin{array}{c}\text { ISaldoI/ } \\
\text { Comércio }\end{array}$} \\
\cline { 2 - 13 } & $1996-1998$ & $2003-2005$ & $1996-1998$ & $2003-2005$ & $1996-1998$ & $2003-2005$ & $1996-1998$ & $2003-2005$ & $1996-19982003-2005$ \\
\hline Primários & 21,5 & 26,4 & 14,0 & 18,9 & 17,5 & 23,4 & $2.896,7$ & $13.705,4$ & 15,4 & 37,1 \\
\hline $\begin{array}{l}\text { Recursos } \\
\text { Naturais }\end{array}$ & 30,1 & 25,7 & 21,5 & 20,8 & 25,6 & 23,8 & $3.022,1$ & $11.865,0$ & 11,0 & 31,7 \\
\hline Trabalho & 11,9 & 10,5 & 9,0 & 7,8 & 10,4 & 9,4 & 885,6 & $5.213,8$ & 7,9 & 35,1 \\
\hline Escala & 22,0 & 21,3 & 17,4 & 14,0 & 19,6 & 18,5 & $1.225,7$ & $11.819,3$ & 5,8 & 40,6 \\
\hline $\begin{array}{l}\text { Fornecedor } \\
\text { Especializado }\end{array}$ & 9,8 & 9,1 & 21,6 & 19,6 & 16,0 & 13,2 & $(7.348,7)$ & $(3.317,3)$ & 42,6 & 16,0 \\
\hline P\&D & 4,7 & 7,0 & 16,4 & 18,9 & 10,9 & 11,7 & $(6.950,1)$ & $(4.863,2)$ & 59,5 & 26,5 \\
\hline Total & 100,0 & 100,0 & 100,0 & 100,0 & 100,0 & 100,0 & $(6.268,7)$ & $34.423,0$ & 5,8 & 21,9 \\
\hline
\end{tabular}

Fonte: Elaboração própria a partir dos dados da Secex. 
Comparando o saldo com o volume de comércio de cada tipo de produto, observa-se que o aumento do superávit foi menos intenso no caso dos produtos primários, em que os aumentos de preços ampliaram tanto as exportações quanto as importações. Já com os produtos intensivos em recursos naturais, em trabalho e em escala, elevados aumentos de exportações foram acompanhados por pequenas elevações de importações, ampliando o superávit com mais intensidade do que o volume de comércio. Já os grupos de produtos com déficit comercial diminuíram o peso deste saldo em relação ao volume de comércio. No caso dos manufaturados intensivos em $\mathrm{P} \& \mathrm{D}$, isto ocorre com forte ampliação tanto das exportações quando das importações, mantendo os pesos desses produtos no comércio exterior brasileiro. Já no caso dos manufaturados produzidos por fornecedores especializados diminuem suas participações nas exportações, nas importações e no comércio.

A peculiar inserção internacional do país não foi um impedimento para a indústria brasileira manifestar sua capacidade de gerar resultados favoráveis na balança comercial, principalmente diante da retomada do comércio internacional após 2002, que favoreceu especialmente as exportações de produtos primários. Este resultado não foi conseqüência apenas do intenso crescimento das exportações de produtos primários e manufaturados, mas também do aumento relativamente pequeno das importações, devido à contenção do crescimento do produto. $\mathrm{O}$ crescimento do produto foi contido por uma política macroeconômica que privilegiou o controle da inflação, obtido através de restrição à expansão monetária, altas taxas de juros, e superávit primário, logrado através de alta carga tributária e baixo nível dos investimentos públicos.

Um crescimento menos contido do produto tenderia a ser acompanhado por um crescimento mais intenso das importações, devido à estrutura da produção industrial existente no país. A abertura comercial dos anos 1990 e a forte entrada de capital entre 1993 e 1997 alteraram substancialmente a estrutura da indústria brasileira. A indústria, que já era uma tradicional importadora de equipamentos, tornou-se também forte demandante de partes e componentes para a montagem de produtos duráveis no país. Dessa forma, o volume global das importações passou a depender não só do nível de investimento, mas também do ritmo da produção industrial doméstica. Como os níveis de investimento e consumo doméstico permaneceram baixos nos últimos anos, o aumento das exportações provocou uma intensa elevação do superávit comercial, pois não foi acompanhada de aumento semelhante nas importações (Laplane; Sarti, 2006).

A obtenção de saldos comerciais favoráveis com crescimento mais intenso e continuado do produto exigiria uma maior taxa de investimento, que permitisse ao país modificar o seu padrão de inserção internacional, alterando as pautas de exportação e importação. Esses investimentos teriam que ampliar a capacidade do país tanto para exportar produtos mais sofisticados para países mais desenvolvidos, quanto para deixar de importar produtos de maior elaboração dos 
países mais desenvolvidos. Para atingir essa taxa de investimento seria necessário não somente um preço do dólar mais estável e em nível adequado para o comércio com outros países, mas também a retomada dos investimentos públicos e da capacidade estatal de articulação dos investimentos privados.

Todos os tipos de produtos contribuíram para a reversão do saldo comercial brasileiro entre 1996-1998 e 2003-2005. Mas, essa contribuição foi maior que o respectivo peso no comércio do país em produtos primários e intensivos em trabalho e escala, e muito próximo deste peso em produtos intensivos em recursos naturais (Tabela 3). Já a redução do déficit em produtos intensivos em $\mathrm{P} \& \mathrm{D}$ e produzidos por fornecedores especializados participou menos da reversão do saldo global do que os respectivos pesos desses tipos de produtos no comércio brasileiro. Entre os tipos de produtos, com forte participação na reversão do saldo comercial, somente os produtos primários aumentaram o peso no comércio do país, confirmando a importância da contenção das importações para a obtenção daquela reversão do saldo comercial.

Tabela 3

Contribuição para a reversão do saldo (valor em US\$ milhões de FOB e taxa em \%)

\begin{tabular}{l|c|c}
\hline & Contribuição & $\%$ \\
\hline Primários & $10.808,8$ & 26,6 \\
\hline Recursos Naturais & $8.843,0$ & 21,7 \\
\hline Trabalho & $4.328,2$ & 10,6 \\
\hline Escala & $10.593,6$ & 26,0 \\
\hline Fornecedor Especializado & $4.031,4$ & 9,9 \\
\hline P\&D & $2.086,8$ & 5,1 \\
\hline Total & $40.691,7$ & 100,0 \\
\hline
\end{tabular}

Fonte: Elaboração própria a partir dos dados da Secex.

De acordo com Prates,

a assimetria entre as pautas de exportação e importação em relação ao grau de intensidade tecnológica resulta em um saldo comercial concentrado em commodities primárias, bens de baixa intensidade tecnológica e intensivos em trabalho e recursos naturais. Em suma, com exceção do superávit no setor de alta intensidade tecnológica (associado, principalmente, às exportações da Embraer), o padrão de inserção comercial da economia brasileira não apresentou mudanças relevantes no governo Lula, seja em termos setoriais, seja em termos de intensidade tecnológica (Prates, 2006).

Avaliando a composição do comércio por região, notamos que a reversão do saldo comercial foi causada tanto pelo aumento do superávit com Aladi e Resto do Mundo quanto pela passagem de um déficit para um superávit com Mercosul, Nafta, União Européia e Ásia. O Nafta e o Resto do Mundo ganharam peso nas exportações brasileiras, em detrimento de Mercosul e União Européia (Tabela 4). 
Tabela 4

Comércio brasileiro por região

(valor em US\$ milhões de FOB, média do período, taxa em \%)

\begin{tabular}{l|c|c|c|c|c|c|c|c|c|c}
\hline & \multicolumn{2}{|c|}{ Exportações } & \multicolumn{2}{c|}{ Importações } & \multicolumn{2}{c|}{ Comércio } & \multicolumn{2}{c|}{ Saldo } & \multicolumn{2}{c}{$\begin{array}{c}\text { ISaldoI/ } \\
\text { Comércio }\end{array}$} \\
\cline { 2 - 13 } & $1996-1998$ & $2003-2005$ & $1996-1998$ & $2003-2005$ & $1996-1998$ & $2003-2005$ & $1996-1998$ & $2003-2005$ & $1996-1998$ & $2003-2005$ \\
\hline Mercosul & 16,6 & 9,1 & 15,9 & 10,4 & 16,2 & 9,6 & $(641,3)$ & $2.393,1$ & 3,7 & 15,8 \\
\hline Aladi & 6,7 & 7,1 & 4,0 & 4,6 & 5,2 & 6,1 & $1.117,7$ & $4.033,0$ & 19,9 & 41,8 \\
\hline Nafta & 21,3 & 25,7 & 27,0 & 20,7 & 24,3 & 23,8 & $(4.559,5)$ & $11.931,2$ & 17,5 & 31,9 \\
\hline União Européia & 28,3 & 23,7 & 29,0 & 26,5 & 28,7 & 24,8 & $(2.154,0)$ & $6.455,3$ & 7,0 & 16,5 \\
\hline Ásia & 13,1 & 14,3 & 13,8 & 19,2 & 13,5 & 16,2 & $(1.197,0)$ & $1.871,4$ & 8,3 & 7,3 \\
\hline Resto do Mundo & 14,0 & 20,0 & 10,4 & 18,6 & 12,1 & 19,5 & $1.165,4$ & $7.738,9$ & 9,0 & 25,2 \\
\hline Total & 100,0 & 100,0 & 100,0 & 100,0 & 100,0 & 100,0 & $(6.268,7)$ & $34.423,0$ & 5,8 & 21,9 \\
\hline
\end{tabular}

Fonte: Elaboração própria a partir dos dados da Secex. 
No caso das importações, nota-se um aumento da participação da Ásia e do Resto do Mundo, com queda do Mercosul, Nafta e União Européia. A composição geográfica do comércio, portanto, é marcada por queda da participação do Mercosul e da União Européia, com conseqüente aumento da Ásia e do Resto do Mundo.

Apesar da alteração nas participações relativas de cada região no comércio brasileiro, o Nafta e a União Européia continuaram tendo a maior participação, mas com uma aproximação da importância da Ásia e do Resto do Mundo. A região que mais contribui para a reversão do saldo comercial no período analisado foi o Nafta, que teve uma reversão de déficit de 4,5 bilhões de dólares para superávit de 11,9 bilhões de dólares (Tabela 5). Era com o Nafta o maior déficit comercial do Brasil e passou a ser o maior superávit do país. As outras regiões que também tiveram uma contribuição significativa para a reversão do saldo de comércio do Brasil foram a União Européia e o Resto do Mundo.

Tabela 5

Contribuição para a reversão do saldo (valor em US\$ milhões de FOB e taxa em \%)

\begin{tabular}{l|c|c}
\hline & Contribuição & $\%$ \\
\hline Mercosul & $3.034,4$ & 7,5 \\
\hline Aladi & $2.915,3$ & 7,2 \\
\hline Nafta & $16.490,8$ & 40,5 \\
\hline União Européia & $8.609,3$ & 21,2 \\
\hline Ásia & $3.068,4$ & 7,5 \\
\hline Resto do Mundo & $6.573,6$ & 16,2 \\
\hline Total & $40.691,7$ & 100,0 \\
\hline
\end{tabular}

Fonte: Elaboração própria a partir dos dados da Secex.

\subsection{Análise do padrão de comércio por tipo de produto}

Analisando o comércio brasileiro de acordo com os indicadores de Fontagné e Freudenberg, que considera o comércio de uma via aquele em que o superávit ou o déficit sejam maiores do que $82 \%$ do comércio de produtos particulares com regiões específicas, notamos que o intenso aumento das exportações e a relativa contenção das importações brasileiras não alteraram o fato de que em todos os tipos de produtos continuou predominando o comércio unilateral (Tabela 6). 
Tabela 6

Avaliação do comércio de acordo com o indicador de Fontagné e Freudenberg (em \%)

\begin{tabular}{l|c|c|c|c|c|c}
\hline \multicolumn{1}{c|}{ 1996-1998 } & Primários & $\begin{array}{c}\text { Recursos } \\
\text { Naturais }\end{array}$ & Trabalho & Escala & $\begin{array}{c}\text { Fornecedor } \\
\text { Especializado }\end{array}$ & P\&D \\
\hline Bilateral Horizontal & 29,1 & 22,6 & 30,6 & 46,1 & 13,5 & 8,5 \\
\hline Bilateral Vertical Superior & 38,9 & 25,5 & 32,4 & 13,8 & 20,9 & 47,3 \\
\hline Bilateral Vertical Inferior & 32,0 & 51,9 & 37,0 & 40,0 & 65,5 & 44,2 \\
\hline Total Bilateral & 2,1 & 7,5 & 14,2 & 28,3 & 25,1 & 12,4 \\
\hline Total Unilateral & 97,9 & 92,5 & 85,8 & 71,7 & 74,9 & 87,6 \\
\hline Total Comércio & 100,0 & 100,0 & 100,0 & 100,0 & 100,0 & 100,0 \\
\hline 2003-2005 & Primários & $\begin{array}{c}\text { Recursos } \\
\text { Naturais }\end{array}$ & Trabalho & Escala & $\begin{array}{c}\text { Fornecedor } \\
\text { Especializado }\end{array}$ & P\&D \\
\hline Bilateral Horizontal & 7,9 & 22,1 & 36,7 & 21,6 & 11,4 & 12,1 \\
\hline Bilateral Vertical Superior & 1,6 & 23,6 & 20,5 & 18,9 & 28,8 & 49,8 \\
\hline Bilateral Vertical Inferior & 90,4 & 54,2 & 42,8 & 59,5 & 59,8 & 38,1 \\
\hline Total Bilateral & 14,3 & 6,8 & 15,4 & 22,6 & 31,6 & 16,0 \\
\hline Total Unilateral & 85,7 & 93,2 & 84,6 & 77,4 & 68,4 & 84,0 \\
\hline Total Comércio & 100,0 & 100,0 & 100,0 & 100,0 & 100,0 & 100,0 \\
\hline Fin
\end{tabular}

Fonte: Elaboração própria a partir dos dados da Secex.

A diferença entre os tipos de produtos com relação ao peso do comércio unilateral reside em que, para produtos primários, intensivos em recursos naturais, manufaturados intensivos em trabalho e em $\mathrm{P} \& \mathrm{D}$, o peso do comércio de uma via é superior a $80 \%$, enquanto para os intensivos em escala e produzidos por fornecedores especializados esta fração é um pouco menor, situando-se entre 70 e $80 \%$.

Os manufaturados intensivos em economias de escala, os produzidos por fornecedores especializados e os intensivos em P\&D seriam, em tese, os tipos de produtos que deveriam ter um maior comércio bilateral. Como foi dito, a tipologia dos produtos tem implícito uma escala de graus de processamento industrial e correspondente avanço tecnológico. O grau de diversificação de produtos e de diferenciação em cada tipo de produto é crescente nesta escala de processamento e conteúdo tecnológico. Os três primeiros tipos de produtos (produtos primários, intensivos em recursos naturais e em trabalho) refletem mais estreitamente a dotação de recursos naturais do país, que inclui a força de trabalho de baixa qualificação profissional. Os outros três tipos de produtos (manufaturados intensivos em economias de escala, produzidos por fornecedores especializados e intensivos em P\&D) exprimem a história do avanço industrial do país, que envolve capacitação tecnológica e desenvolvimento da força de trabalho profissionalmente qualificada. 
No caso dos produtos próximos da base de recursos naturais (que inclui a população sem qualificação profissional especial), o comércio com outro país pressupõe que este tenha uma base de recurso natural diferente, e este comércio seria, portanto, intersetorial. No caso dos produtos mais afastados da base de recurso natural, é possível que exista um comércio intra-setorial de variedades diferentes dos produtos, refletindo economias de escala estáticas e dinâmicas. Esta possibilidade tende a ocorrer no comércio entre dois países com graus semelhante e elevado de desenvolvimento industrial. Porém, no comércio entre países com nível de desenvolvimento industrial diferente, a possibilidade de comércio intrasetorial pode envolver diferenças de qualidade dos produtos, levando a distinguir, neste comércio intra-industrial, o horizontalmente diferenciado (variedades dentro de uma mesma qualidade do produto) do verticalmente diferenciado (qualidades diferentes do produto). Essa possibilidade de comércio intra-industrial verticalmente diferenciado tende a ocorrer entre blocos econômicos que reúnem países com graus de desenvolvimento industrial diferentes. As preferências de comércio dentro do bloco aumentam as possibilidades do país menos desenvolvido competir com os países fora do bloco nas exportações dos produtos industriais menos desenvolvidos. Na verdade, sem a interferência de preferências comerciais estabelecidas por acordos entre países, o comércio intra-industrial tende a ser horizontalmente diferenciado, envolvendo países com graus semelhantes de desenvolvimento industrial. Nos países de grau intermediário de desenvolvimento industrial, mesmo no caso dos produtos mais afastados da base de recursos naturais, o comércio tende a ser intersetorial.

A análise do comércio entre países não pode deixar de levar em conta o fato de que uma parte considerável deste comércio é realizada dentro de grandes empresas multinacionais. O comércio intra-empresa pode reforçar o comércio intra-setorial, de modo análogo aos acordos que formam blocos econômicos, inclusive porque a empresa multinacional pode contribuir para acordos entre países de preferência comercial para determinados tipos de produtos. Dependendo da estratégia da empresa multinacional, o tipo de comércio entre esses países (inter ou intra-setorial, horizontal ou vertical) depende da posição do menos desenvolvido na estrutura de localização e geração de valor agregado construída pelas multinacionais. A consideração do comércio intra-empresa reforça também a suposição de que os manufaturados intensivos em economias de escala, produzidos por fornecedores especializados e intensivos em $\mathrm{P} \& \mathrm{D}$ deveriam ter um maior comércio bilateral. A produção internacionalizada desses produtos pelas grandes corporações envolve intenso comércio dentro da própria empresa, entre filiais e destas com a matriz. Tal comércio é fundamentalmente intra-industrial, articulando as diversas etapas dos processos de produção realizados em distintos países. 
De um modo geral, o comércio brasileiro confirma a hipótese anterior de que os produtos de maior elaboração industrial tendem a apresentar um maior comércio intra-setorial, embora a fração do comércio de duas vias, como já foi dito, seja bastante reduzida, mesmo com estes tipos de produtos. $\mathrm{O}$ caso dos manufaturados intensivos em $\mathrm{P} \& \mathrm{D}$ sai um pouco desta regra, sendo, nos dois períodos, o comércio bilateral menor do que $15 \%$ do comércio deste tipo de produto.

Nesses produtos de maior elaboração, observa-se uma redução do comércio bilateral para os manufaturados intensivos em escala e uma elevação deste comércio para os manufaturados produzidos por fornecedores especializados e intensivos em P\&D. No primeiro caso esta queda ocorreu pela redução do comércio bilateral horizontal, ou seja, aquele em que os valores unitários das exportações e importações são parecidos. Verifica-se também, para este tipo de produto, um aumento do comércio bilateral vertical inferior, que são aqueles produtos em que a qualidade de nossas exportações é mais baixa do que a de nossas importações. Já os manufaturados produzidos por fornecedores especializados e os intensivos em P\&D tiveram elevação do comércio de duas vias que ocorreu, entretanto, com diminuição do comércio vertical inferior. Nos três casos, a participação mais significativa do comércio bilateral continua sendo a do comércio vertical inferior.

Assim, mesmo os casos de aumento do comércio bilateral com produtos de tecnologia relativamente sofisticada, o padrão do comércio brasileiro não é aquele que se esperaria favorecer a ampliação do valor agregado no país, e consequentemente sua contribuição para o crescimento do conjunto da economia. $\mathrm{O}$ aumento das exportações desses tipos de produtos tecnologicamente mais sofisticados para países mais desenvolvidos foi obtido fundamentalmente pelo fornecimento de insumos menos sofisticados nas redes de produção e geração de valor agregado das grandes empresas multinacionais.

Já os produtos primários, os intensivos em recursos naturais e os manufaturados intensivos em trabalho confirmam o que, em tese, se esperaria deles, ou seja, um alto peso do comércio unilateral. A exportação de produtos primários reflete vantagens comparativas do país de dispor dos recursos naturais apropriados. Os produtos intensivos em recursos naturais e em trabalho, embora envolvam certo processamento industrial, apenas os países mais desenvolvidos conseguiram sofisticar esses produtos, incorporando tecnologia ou controlando os elos chaves na cadeia de valor (marcas, redes de distribuição, etc.).

O peso do comércio bilateral com estes tipos de produtos continua pequeno, mas mudou sua composição. Em 1996-1998, somente com produtos intensivos em recursos naturais a maior parte do comércio bilateral era vertical 
inferior, ou seja, o valor unitário da importação era muito maior do que o da exportação. Nos outros dois tipos de produtos (produtos primários e intensivos em trabalho) os pesos do horizontal, vertical superior e vertical inferior eram relativamente uniformes. Em 2003-2005, o comércio bilateral com estes tipos de produtos passou a ser fundamentalmente vertical inferior, principalmente no caso dos produtos primários.

Ou seja, o recente crescimento das exportações, com lento crescimento do PIB e preço do dólar relativamente alto em 2002, confirmou o caráter unilateral do comércio com produtos primários, intensivos em recursos naturais e em trabalho. A pouca participação do comércio bilateral com estes tipos de produtos reforçou a concentração do país em produtos de baixo valor agregado, com importação de produtos mais sofisticados, não favorecendo a ampliação do valor agregado no país e a contribuição da produção desses produtos para o crescimento do conjunto da economia. Países mais desenvolvidos industrialmente foram capazes de ampliar o valor agregado de produtos manufaturados intensivos em recursos naturais e em trabalho, pela incorporação de tecnologia, sofisticando os produtos elaborados.

\subsection{Análise do padrão de comércio por região}

Analisando o comércio brasileiro por região, notamos que também predomina o comércio de uma via. O maior peso do comércio bilateral ocorre com o Mercosul, um bloco econômico do qual o Brasil faz parte e contém um parceiro importante com grau de desenvolvimento semelhante (Tabela 7). Com a formação do Mercosul, as grandes corporações multinacionais presentes no Brasil e na Argentina passaram a ter por objetivo vender os seus produtos no mercado regional. Como muitas dessas empresas estão presentes em ambos os países, elas são as principais responsáveis pelo comércio intra-industrial do Brasil com o Mercosul. O peso do comércio bilateral com esta região continuou entre 35 e 40\%, ao se compararem os períodos 1996-1998 e 2003-2005, mas o comércio bilateral horizontal, que representava, no primeiro período, cerca da metade do comércio bilateral do Brasil com esta região, diminuiu para cerca de um terço, tendo por contrapartida principalmente o aumento da participação do comércio bilateral vertical inferior. O Mercosul, portanto, ao reduzir o seu peso no comércio brasileiro (16,2\% para 9,6\%), manteve a composição por tipo de comércio (uma ou duas vias), mas alterou a composição do comércio de duas vias, tendo aumentado a parcela deste tipo de comércio, em que as importações do Mercosul têm um valor médio superior ao das exportações brasileiras para esta região. $\mathrm{Ou}$ seja, este último tipo de comércio diminuiu muito menos que os demais tipos de comércio do Brasil com o Mercosul. 
Carolina Troncoso Baltar

Tabela 7

Avaliação do comércio por região de acordo com o indicador de Fontagné e Freudenberg (em \%)

\begin{tabular}{l|c|c|c|c|c|c}
\hline \multicolumn{1}{|c|}{$1996-1998$} & Mercosul & Aladi & Nafta & $\begin{array}{c}\text { União } \\
\text { Européia }\end{array}$ & Ásia & $\begin{array}{c}\text { Resto do } \\
\text { Mundo }\end{array}$ \\
\hline Bilateral Horizontal & 52,8 & 23,7 & 7,9 & 16,0 & 11,0 & 18,2 \\
\hline Bilateral Vertical Superior & 19,9 & 44,4 & 22,0 & 25,1 & 46,0 & 24,3 \\
\hline Bilateral Vertical Inferior & 27,3 & 31,9 & 70,0 & 58,9 & 43,0 & 57,5 \\
\hline Total Bilateral & 37,5 & 4,8 & 19,8 & 9,2 & 3,2 & 3,9 \\
\hline Total Unilateral & 62,5 & 95,2 & 80,2 & 90,8 & 96,8 & 96,1 \\
\hline Total Comércio & 100,0 & 100,0 & 100,0 & 100,0 & 100,0 & 100,0 \\
\hline \multicolumn{1}{|c|}{ 2003-2005 } & Mercosul & Aladi & Nafta & União & Aursia & $\begin{array}{c}\text { Resto do } \\
\text { Mundo }\end{array}$ \\
\hline Bilateral Horizontal & 34,9 & 29,7 & 11,7 & 17,2 & 12,4 & 3,7 \\
\hline Bilateral Vertical Superior & 24,4 & 8,7 & 25,0 & 27,1 & 52,1 & 6,2 \\
\hline Bilateral Vertical Inferior & 40,7 & 61,5 & 63,2 & 55,7 & 35,5 & 90,2 \\
\hline Total Bilateral & 36,7 & 8,1 & 22,7 & 12,9 & 3,8 & 17,5 \\
\hline Total Unilateral & 63,3 & 91,9 & 77,3 & 87,1 & 96,2 & 82,5 \\
\hline Total Comércio & 100,0 & 100,0 & 100,0 & 100,0 & 100,0 & 100,0 \\
\hline
\end{tabular}

Fonte: Elaboração própria a partir dos dados da Secex

O comércio brasileiro com o Resto do Mundo foi o que mais aumentou no período (12,1\% para $19,5 \%$ do total do comércio brasileiro). Este aumento de comércio foi obtido com elevação substantiva do comércio bilateral (3,9\% para 17,5\% do comércio do Brasil com o Resto do Mundo), especialmente o vertical inferior (57,5\% para 90,2\% do comércio bilateral entre o Brasil e o Resto do Mundo). Em outras palavras, a enorme ampliação do comércio do Brasil com o Resto do Mundo foi em duas vias, e com valor médio das importações brasileiras maior do que o das exportações para esta parte do mundo. Nas demais regiões, mesmo na Ásia, que aumentou de peso no comércio brasileiro, e na União Européia, que reduziu este peso, não se alterou substancialmente a participação do comércio de uma via. Este tipo de comércio do Brasil com estas regiões reflete a diferença entre os graus de desenvolvimento do Brasil e dos países que conformam cada uma dessas regiões. Países com graus de desenvolvimento diferentes intercambiam produtos diferentes. No caso do Resto do Mundo, o aumento do peso do comércio bilateral reflete o caráter residual desta agrupação de países. O Brasil exporta determinados produtos para alguns países do Resto do Mundo e importa esses produtos de outros países.

Além do Mercosul, o peso do comércio bilateral é também mais expressivo com o Nafta (cerca de 20\%). O comércio do Brasil com o Nafta, entretanto, é diferente do comércio com o Mercosul, pois não se trata de um bloco 
econômico com parceiros com grau de desenvolvimento semelhante. Uma parte importante do comércio do Brasil com o Nafta realiza-se dentro de empresas multinacionais americanas e européias, e este comércio em duas vias é fundamentalmente vertical inferior (cerca de dois terços do comércio bilateral do Brasil com o Nafta).

\subsection{Análise do padrão de comércio por tipo de produto e região}

Num apanhado global da distribuição regional do comércio, nos três tipos de produtos em que se esperaria um alto peso do comércio unilateral (produtos primários, intensivos em recursos naturais e em trabalho), esta distribuição modificou-se mais no caso dos produtos primários do que para os produtos intensivos em recursos naturais e em trabalho (Tabela 8). Nesses dois tipos de produtos, cai a participação no comércio brasileiro do Mercosul e da União Européia, não se altera a da Aladi e aumenta a do Resto do Mundo. Essas variações, entretanto, foram mais pronunciadas no caso dos produtos primários. Além disso, somente no comércio brasileiro com este ultimo tipo de produto, cai o peso do Nafta e aumenta o da Ásia.

Já no caso dos produtos em que se esperaria um maior peso do comércio bilateral (manufaturados intensivos em economias de escala, produzidos por fornecedores especializados e intensivos em P\&D), em todos eles ocorreram mudanças significativas na distribuição regional do comércio com estes tipos de produtos. Apesar dos problemas do Mercosul, o peso da América do Sul (Mercosul mais Aladi) diminuiu substancialmente apenas no comércio dos produtos intensivos em economias de escala, tendo aumentado no comércio de manufaturados intensivos em P\&D. A Ásia aumentou sua participação no comércio de manufaturados produzidos por fornecedores especializados e intensivos em $\mathrm{P} \& \mathrm{D}$, enquanto a União Européia perdeu participação no comércio com esses produtos. Nafta ganhou participação principalmente no comércio de manufaturados intensivos em escala e o Resto do Mundo aumentou sua participação nos três tipos de produtos.

Em resumo, o aumento do peso do Resto do Mundo no comércio brasileiro ocorreu em todos os tipos de produtos. Já os declínios das participações do Mercosul e da União Européia verificaram-se também em todos os tipos de produtos. A Ásia aumentou sua participação no comércio brasileiro com produtos primários, de um lado, e de fornecedores especializados e intensivos em P\&D, de outro. Finalmente, Nafta e Aladi tiveram poucas alterações em suas respectivas participações no comércio brasileiro com os vários tipos de produtos. 
Tabela 8

Avaliação do comércio por tipo de produto e região (em \%)

\begin{tabular}{|c|c|c|c|c|c|c|c|c|c|c|c|c|}
\hline & \multicolumn{2}{|c|}{ Primários } & \multicolumn{2}{|c|}{ Recursos Naturais } & \multicolumn{2}{|c|}{ Trabalho } & \multicolumn{2}{|c|}{ Escala } & \multicolumn{2}{|c|}{ Forn Especializado } & \multicolumn{2}{|c|}{$\mathrm{P} \& \mathrm{D}$} \\
\hline & 1996-1998 & 2003-2005 & 1996-1998 & 2003-2005 & 1996-1998 & $82003-2005$ & 1996-1998 & 2003-2005 & 1996-1998 & 2003-2005 & 1996-1998 & 2003-2005 \\
\hline Mercosul & 19,7 & 6,9 & 12,7 & 8,3 & 18,1 & 14,1 & 27,3 & 16,2 & 10,0 & 7,2 & 6,7 & 6,5 \\
\hline Aladi & 5,8 & 6,1 & 5,1 & 5,2 & 6,0 & 6,1 & 6,9 & 9,2 & 4,0 & 4,9 & 2,7 & 4,5 \\
\hline Nafta & 11,8 & 7,8 & 20,4 & 22,9 & 28,2 & 27,3 & 23,4 & 29,2 & 33,6 & 33,1 & 37,8 & 35,5 \\
\hline União Européia & 29,2 & 24,4 & 29,7 & 27,0 & 22,7 & 20,7 & 22,5 & 20,5 & 37,2 & 31,4 & 29,8 & 23,9 \\
\hline Ásia & 13,2 & 20,3 & 11,3 & 10,7 & 14,4 & 14,0 & 14,0 & 14,7 & 12,1 & 15,8 & 19,2 & 23,5 \\
\hline Resto do Mundo & 20,2 & 34,5 & 20,9 & 25,8 & 10,5 & 17,8 & 5,9 & 10,1 & 3,2 & 7,5 & 3,9 & 6,1 \\
\hline Total & 100,0 & 100,0 & 100,0 & 100,0 & 100,0 & 100,0 & 100,0 & 100,0 & 100,0 & 100,0 & 100,0 & 100,0 \\
\hline
\end{tabular}

Fonte: Elaboração própria a partir dos dados da Secex. 


\section{Conclusão}

Num quadro de intenso crescimento do comércio mundial, o Brasil reverteu o déficit de comércio e passou a usufruir de expressivo superávit. A política macroeconômica do país conteve o consumo e o investimento, e neste contexto o aumento das exportações mostrou-se insuficiente para induzir um crescimento mais expressivo do PIB. Desde a desvalorização do Real, em 1999, a política macroeconômica priorizou o combate à inflação, através de uma política monetária contracionista, administrando uma enorme dívida pública, por meio de superávit primário, obtido com alta carga tributária e redução do investimento público. A incerteza provocada pela perspectiva de vitória da oposição na eleição de 2002, e eventual alteração nas linhas de política monetária, perturbou a eficácia desta estratégia, ao motivar uma acentuação da fuga de capitais. O preço do dólar aumentou fortemente, ampliando as possibilidades de aumento da inflação. Diante deste quadro, o novo governo optou por dar continuidade à política macroeconômica, acentuando seus principais aspectos, ao elevar ainda mais o nível das taxas de juros e do superávit primário. Um dos objetivos principais era reverter a subida do preço do dólar. O crescimento do comercio mundial, repercutindo nas exportações brasileiras, num quadro de pouco crescimento do PIB, levou a enorme superávit comercial, que permitiu reduzir a dívida externa e ampliar as reservas internacionais. O preço do dólar diminuiu fortemente, apesar do aumento das reservas, devido ao montante do superávit comercial e às operações no mercado futuro de dólar, motivado pelas altas taxas de juros.

A atual apreciação cambial tem origem diferente da verificada na década de 1990. Esta última foi provocada por intensa entrada de capital, que cobriu imensos déficits de conta corrente, que se acumularam desde 1994. Já a atual apreciação cambial está relacionada com o superávit de comércio, que provocou superávit de conta corrente do balanço de pagamentos. $\mathrm{Na}$ política macroeconômica dos dois períodos sobressai a contenção monetária, que elevou o nível das taxas de juros. No primeiro período, as altas taxas de juros visaram preservar a entrada de capital e evitar uma fuga (que desvalorizaria o Real e aumentaria a inflação), diante de sucessivas crises financeiro/cambial que ocorreram em países emergentes ao longo da década de 1990. No segundo período, a contenção monetária assentou a valorização do Real, estimulando transações financeiras de arbitragem da taxa de juros, procurando reduzir a inflação em meio a um aumento generalizado dos preços internacionais das commodities.

A insuficiência do aumento das exportações para induzir maior crescimento do PIB está relacionada com a pequena participação do comércio no tamanho da economia brasileira e com as características desse comércio, em termos das pautas de exportação e importação, que limitam os efeitos dinâmicos 
da ampliação do comércio sobre o crescimento do PIB. O Brasil exporta produtos primários e semi-elaborados para países em desenvolvimento, e produtos manufaturados de nível tecnológico intermediário para países em desenvolvimento, importando dos países desenvolvidos produtos manufaturados de alto nível tecnológico, e de países em desenvolvimento produtos primários e semi-elaborados. A potencialidade de geração de valor agregado e de efeitos dinâmicos do comércio exterior sobre o PIB é tanto maior quanto maior for o nível de sofisticação tecnológica dos produtos exportados vis-à-vis os importados, e quanto maior for o peso das exportações desses produtos para os países desenvolvidos, onde é maior a demanda por esses produtos. As peculiaridades das pautas de exportação e importação não são favoráveis ao crescimento da economia brasileira, mas contêm algum potencial, que pode ser desenvolvido. Essas características do comércio exterior brasileiro, entretanto, não foram alteradas pelo intenso crescimento das exportações.

Na verdade, uma mudança mais profunda do padrão de comércio exigiria alterações na estrutura produtiva da economia brasileira que pressuporiam um nível de investimento muito maior do que o verificado. Tais investimentos teriam que ampliar e melhorar a infra-estrutura, capacitar o país para elaborar produtos de maior elaboração tecnológica, prescindindo de importações, e para consolidar suas exportações de produtos de nível tecnológico intermediário para países em desenvolvimento e ampliar o peso dos produtos tecnologicamente mais sofisticados na pauta de exportação, logrando exportá-los para países desenvolvidos. Isto não quer dizer que as exportações teriam necessariamente que se constituir no motor do crescimento em um país com as dimensões do Brasil. Trata-se apenas de melhorar as pautas de importação e exportação, de modo a obter os saldos comerciais necessários para cobrir os déficits da conta de serviços do balanço de pagamentos, em meio a um crescimento mais intenso do produto, fundamentalmente explicado pela retomada dos investimentos e pelo aumento do consumo.

A análise do comércio, utilizando a metodologia de Fontagné e Freudenberg, mostra que o comércio brasileiro era e continua fundamentalmente unilateral, ou seja, a maior parte do comércio nacional envolve déficit ou superávit de mais de $82 \%$, considerando produtos e regiões específicas. Isto ocorreu não somente com os produtos primários e os intensivos em recursos naturais e em trabalho, mas também com os manufaturados intensivos em escala, produzidos por fornecedores especializados e intensivos em P\&D. O país exporta esses manufaturados com alguma sofisticação tecnológica para países em desenvolvimento e importa este tipo de produto com maior sofisticação tecnológica de países desenvolvidos. 
Nos países desenvolvidos, o crescimento do comércio envolveu ampliação da participação do comércio intra-industrial, refletindo o aumento da importância do intercambio dos próprios países desenvolvidos. Este comércio permitiu ampliar a variedade de produtos e aproveitar melhor as economias de escala e de aprendizado tecnológico, contribuindo para o desenvolvimento dessas economias. Este padrão de comércio favorece a agregação de valor e permite que uma intensificação do comércio tenha um forte impacto sobre o crescimento dessas economias. Nos países em desenvolvimento que melhor aproveitaram a situação internacional, o crescimento do comércio envolveu ampliação da exportação para países desenvolvidos, de produtos com crescente conteúdo tecnológico e de agregação de valor.

O padrão do comércio brasileiro não tem essas características. O país importa produtos de alto conteúdo tecnológico e valor agregado dos países mais desenvolvidos e exporta para estes produtos de menor valor agregado e sofisticação tecnológica. São para países menos desenvolvidos que o Brasil consegue exportar produtos com alguma sofisticação tecnológica e valor agregado. Isto se reflete não somente na predominância da unilateralidade do comércio brasileiro, mas também no fato de que, quando o comércio de duas vias tem alguma importância, tem prevalecido o comércio vertical inferior, ou seja, aquele em que os produtos exportados pelo Brasil têm um valor unitário bem menor do que os importados.

Este padrão de comércio não impediu que, em circunstancias favoráveis do comércio mundial, o país fosse capaz de reverter um déficit de comércio e obter um expressivo superávit comercial. O crescimento das exportações, entretanto, teve pouco impacto sobre o valor agregado dos setores exportadores e limitada contribuição para o crescimento global da economia brasileira. Este crescimento do PIB tem sido muito pequeno por conta da política macroeconômica, que tem limitado o investimento e o consumo doméstico, contribuindo para a obtenção do expressivo superávit comercial. A recuperação progressiva do valor do salário mínimo, o crescimento do emprego formal, reajustes salariais acima da inflação, tem aumentado a massa de salários, e a implementação de mecanismos especiais de crédito ao consumo (por exemplo o crédito consignado com desconto na folha de pagamento, que permite a cobrança de uma menor taxa de juros) provocou uma retomada do consumo em 2006. O prosseguimento do aumento do consumo e a ampliação dos investimentos necessários para o crescimento continuado e intenso da economia, entretanto, requerem uma modificação da política macroeconômica, no sentido de relaxar a política de contenção monetária, de modo a permitir, de um lado, o atendimento da demanda de crédito com melhores condições de prazo e taxas de juros, e de outro, diminuir o impacto do serviço da dívida pública sobre o orçamento, viabilizando 
as ações públicas necessárias ao crescimento da economia. Além disso, será também importante que a retomada dos investimentos altere a estrutura produtiva da economia nacional, de modo, de um lado, a recuperar a infra-estrutura, e, de outro, a permitir melhorar o padrão de comércio, a fim de que o crescimento das exportações e eventual substituição de importações permitam contornar restrições de divisas, que poderiam ocorrer com um crescimento mais intenso do produto nacional.

A relação entre comércio e crescimento, portanto, não é simples e automática, sendo necessária a realização de investimentos, não somente na infraestrutura do país, mas também em substituição de importações e na diversificação da pauta exportadora, com maior transformação industrial e agregação de valor na economia. O estudo do assunto ressalta a importância do conteúdo do comércio. A inserção mundial do Brasil não permitiu ao país aproveitar todas as oportunidades, porque não ocorreram os investimentos necessários, mas ao menos o país foi capaz de obter saldo positivo da conta corrente do balanço de pagamentos, reduzindo assim sua vulnerabilidade externa. A expansão das exportações brasileiras, entretanto, não se restringiu a produtos primários e intensivos em recursos naturais. A análise mais detalhada das pautas de comércio indica alguma potencialidade do país para melhorar sua inserção internacional se for capaz de realizar os investimentos necessários.

Pela literatura, sabemos que houve aumento do comércio de manufaturados entre os países, e que boa parte destas trocas são feitas dentro das grandes corporações. Essas multinacionais passaram a ter uma produção mais dispersa geograficamente, com as regiões se especializando em determinados produtos. A metodologia utilizada no trabalho, ao avaliar o tipo do comércio brasileiro, pode examinar o quanto o Brasil está inserido neste comércio de manufaturados. Notamos que prevaleceu o comércio unilateral e que o pouco comércio bilateral foi fundamentalmente vertical inferior. O resultado seria uma menor contribuição para a agregação de valor da economia. Porém, é importante observar que no pequeno peso do comércio bilateral, há uma participação não desprezível do comércio horizontal ou mesmo do vertical superior, em manufaturados intensivos em economias de escala, produzidos por fornecedores especializados e intensivos em P\&D. Além disso, este comércio realizou-se com países do Nafta, União Européia e Ásia.

Assim, apesar do comércio de duas vias ainda ser pequeno e prevalecer neste comércio o comércio inferior, quando se abre por categoria e por região, notamos que existem formas de inserção mais ricas, com potencial dinamizador para o crescimento, que podem ser desenvolvidas se forem realizados os investimentos necessários. Além disso, é melhor para o país se inserir no comércio bilateral, mesmo que seja num comércio inferior, do que não participar deste tipo 
de comércio. Dessa maneira, podemos concluir que, apesar do comércio brasileiro não apresentar atualmente as características mais favoráveis para o crescimento e o desenvolvimento da economia nacional, é possível melhorar a situação havendo investimentos. Cabe ao país conseguir aprofundar sua inserção nestes setores e investir na continuação do desenvolvimento industrial para que o Brasil volte a crescer, com um comércio que contribua para o dinamismo da economia.

\section{Bibliografia}

BALTAR, Carolina Troncoso. Padrão do comércio brasileiro no período 2003-2005: um estudo do conteúdo dos fluxos de importação e exportação. 2007. Dissertação (Mestrado)Instituto de Economia, Universidade Estadual de Campinas, Campinas, SP, 2007.

FONTAGNÉ, Lionel; FREUDENBERG, Michael. Intra-industry trade methodological issues reconsidered. Working Papers Released by CEP II, 1997. (Document de travail, n. 97-01).

HOLLAND, M.; XAVIER, C. L. Dinâmica e competitividade setorial das exportações brasileiras: uma análise de painel para o período recente. Economia e Sociedade, Campinas, n. 24, jan./jun. 2005.

LAPLANE, Mariano; SARTI, Fernando. Prometeu acorrentado: o Brasil na indústria mundial. In: CARNEIRO, Ricardo (Org). A supremacia dos mercados e a política econômica do Governo Lula. São Paulo: Editora Unesp, 2006.

NASSIF, André. Há evidências de desindustrialização no Brasil? Rio de Janeiro: BNDES, 2006. (Texto para Discussão, n. 108).

PRATES, Daniela Magalhães. A inserção da economia brasileira no Governo Lula. In: CARNEIRO, Ricardo (Org). A supremacia dos mercados e a política econômica do Governo Lula. São Paulo: Editora Unesp, 2006.

SARTI, Fernando; SABBATINI, Rodrigo. Conteúdo tecnológico do comércio exterior brasileiro. In: VIOTTI, Eduardo Baumgratz; MACEDO, Mariano de Matos (Org). Indicadores de ciência, tecnologia e inovação no Brasil. Campinas, SP: Editora Unicamp, 2003.

THIRLWALL, A. P. Alternative approaches to the analysis of economic growth. Based on Lectures given at the National University of Mexico, Sept. 2000. 
Anexo

Países que pertencem a cada uma das regiões

\begin{tabular}{|c|c|c|c|c|c|}
\hline Mercosul & $\begin{array}{l}\text { Argentina } \\
\text { Paraguai } \\
\text { Uruguai }\end{array}$ & & & & \\
\hline \multirow{3}{*}{ Nafta } & Canadá & & & & \\
\hline & Estados Unidos & & & & \\
\hline & México & & & & \\
\hline \multirow{4}{*}{ Aladi } & Bolívia & Peru & & & \\
\hline & Chile & Venezuela & & & \\
\hline & Colômbia & & & & \\
\hline & Equador & & & & \\
\hline \multirow{5}{*}{ União Européia } & Alemanha & Finlândia & Luxemburgo & & \\
\hline & Áustria & França & Países Baixos & & \\
\hline & Bélgica & Grécia & Portugal & & \\
\hline & Dinamarca & Irlanda & Suécia & & \\
\hline & Espanha & Itália & & & \\
\hline \multirow{5}{*}{ Ásia } & China & Indonésia & & & \\
\hline & Taiwan (Formosa) & Japão & & & \\
\hline & Coréia do Sul & Malásia & & & \\
\hline & Filipinas & Singapura & & & \\
\hline & Hong Kong & Tailândia & & & \\
\hline \multirow{38}{*}{$\begin{array}{l}\text { Resto do } \\
\text { Mundo }\end{array}$} & Afeganistão & Congo & Islândia & Nigéria & Serra Leoa \\
\hline & Albânia & Coréia do Norte & Israel & Norfolk, Ilha & Síria \\
\hline & Burkina Faso & Costa do Marfim & Iugoslávia & Noruega & Somália \\
\hline & Andorra & Croácia & Jamaica & Nova Caledônia & Siri Lanka \\
\hline & Angola & Costa Rica & Jordânia & Papua Nova Guiné & Suazilândia \\
\hline & Anguilla & Coveite & Kiribati & Nova Zelândia & África do Sul \\
\hline & Antigua Barbuda & Cuba & Laos & Vanuatu & Sudão \\
\hline & Antilhas Holandesas & Benin & Lesoto & Omã & Suíça \\
\hline & Arábia Saudita & Dominica & Letônia & Pacif.il.dos EUA & Suriname \\
\hline & Argélia & Egito & Líbano & Palau & Tadjiquistão \\
\hline & Armenia & Eritréia & Libéria & Paquistão & Tanzânia \\
\hline & Aruba & Emirados Arábes & Líbia & Panamá & Djibuti \\
\hline & Austrália & Eslovênia & Liechtenstein & Polinésia Francesa & Chade \\
\hline & Azerbaijão & Eslovaca, Rep. & Lituânia & Polônia & Tcheca, República. \\
\hline & Bahamas & Estônia & Macau & Porto Rico & Timor Oriental \\
\hline & Barein & Etiópia & Macedônia & Quênia & Togo \\
\hline & Bangladesh & Feroe, Ilhas & Madagascar & Quirguizia & Tonga \\
\hline & Barbados & Gabão & Madeira, Ilha da & Reino Unido & Trinidad e Tobago \\
\hline & Belarus & Gâmbia & Malavi & $\begin{array}{l}\text { Rep.Centro } \\
\text { Africana. }\end{array}$ & Tunísia \\
\hline & Belize & Gana & Maldivas & Rep.Dominicana & Turcas e Caicos \\
\hline & Bermudas & Geórgia & Mali & Reunião & Turcomenistão \\
\hline & Mianma & Gibraltar & Malta & Zimbabue & Turquia \\
\hline & Bosnia-Herzegovina & Granada & Marianas do Norte & Romênia & Ucrânia \\
\hline & Botswana & Guadalupe & Marrocos & Ruanda & Uganda \\
\hline & Brunei Darussalam & Guam & Marshall, Ilha & Rússia & Uzbequistão \\
\hline & Bulgária & Guatemala & Martinica & Salomão, Ilhas & Vietnã \\
\hline & Burundi & Guiana francesa & Maurício & Saara Ocidental & Virgens,Ilh.Br. \\
\hline & Butão & Guiné & Mauritânia & El Salvador & Virgens,Ilh.Eua \\
\hline & Cabo Verde & Guiné Equatorial & Moldávia & Samoa & Fiji \\
\hline & Cayman, Ilhas & Guiné -Bissau & Mônaco & Samoa Americana & Wake,Ilha \\
\hline & Camboja & Guiana & Mongólia & S.Crist.e Nevis & Congo \\
\hline & Camarões & Haiti & Micronésia & San Marino & Zâmbia \\
\hline & Canárias,Ilhas & Honduras & Montserrat & São Vicente & Prov.Nav.e Aeron \\
\hline & Casaquistão & Hungria & Moçambique & Santa Helena & \\
\hline & Catar & Iêmem & Namíbia & Santa Lúcia & \\
\hline & Chipre & Índia & Nepal & S.Tomé e Príncipe & \\
\hline & Cocos-Keeling,i. & Iraque & Nicarágua & Senegal & \\
\hline & Comores & Irã & Níger & Seychelles & \\
\hline
\end{tabular}

